\title{
The association of obesity and serum leptin levels with complete blood count and some serum biochemical parameters in Iranian overweight and obese individuals
}

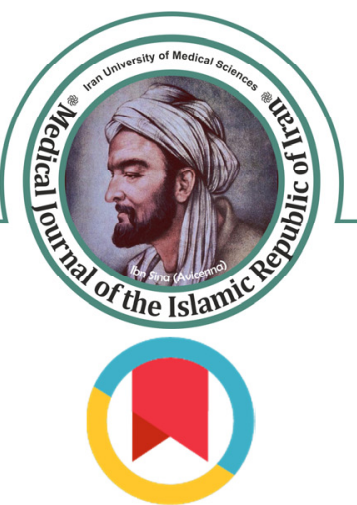

\author{
Mitra Zarrati ${ }^{1}$, Nahid Aboutaleb ${ }^{2}$, Elhameh Cheshmazar ${ }^{1}$, Raheleh Shokouhi Shoormasti ${ }^{3}$, Elham Razmpoosh ${ }^{4}$, \\ Farinaz Nasirinezhad*5
}

Received: 21 Nov 2017

Published: 22 Jul 2019

\section{Abstract}

Background: Obesity has been suggested to be well correlated with altered levels of complete blood count (CBC) parameters. In this study, the relationship of body mass index (BMI) and circulating leptin levels with CBC among obese and overweight adults was examined.

Methods: $\mathrm{CBC}$ and biochemical parameters, $\mathrm{WBC}$ and hematological profiles, leptin levels, related factors to liver, and kidney and lipid profiles were measured among 184 obese and overweight people aged 18-60 years. Statistical analysis was performed using SPSS software. To assess the normality of data, the Kolmogorov-Smirnov test was used. Logarithmic transformation was performed for some variables with non-normal distribution. The association between 2 quantitative variables was measured using bivariate correlation (Pearson or Spearman). Pearson correlations and multiple regression analysis were performed to assess the correlation between variables. Simple and multiple regression analyses were performed to predict some variables. P- value $<0.05$ was considered significant.

Results: Hematocrit, insulin, fasting blood sugar, uric acid, TG, LDL-C, VLDL-C, and ALT were positively correlated with BMI $(\mathrm{p}=0.041, \mathrm{r}=0.149$ for hematocrit; $\mathrm{p} \leq 0.001, \mathrm{r}=0.520$ for insulin; $\mathrm{p} \leq 0.001, \mathrm{r}=0.363$ for $\mathrm{FBS} ; \mathrm{p} \leq 0.001, \mathrm{r}=0.309$ for uric acid; $\mathrm{p}=0.015$, $\mathrm{r}=0.189$ for TG; $\mathrm{p}=0.030, \mathrm{r}=161$ for LDL-C; $\mathrm{p}=0.019, \mathrm{r}=0.181$ for VLDL-C; $\mathrm{p} \leq 0.001, \mathrm{r}=0.299$ for ALT), whereas urea and HDL-C were negatively correlated with BMI ( $\mathrm{p} \leq 0.001, \mathrm{r}=-0.368$ for urea; $\mathrm{p} \leq 0.001, \mathrm{r}=-0.297$ for HDL-C). Moreover, LDL-C and insulin were positively correlated with leptin ( $\mathrm{P}=0.011, \mathrm{r}=0.194$ for LDL-C, $\mathrm{P}=0.013, \mathrm{r}=0.114$ for insulin) and hematocrit, urea, creatinine, TG and VLDL-C were negatively correlated with leptin $(p=0.040, r=-0.162$ for hematocrit; $p \leq 0.001, r=-0.305$ for urea; $p=0.007, r=-0.219$ for creatinine; $\mathrm{p}=0.025, \mathrm{r}=0.188$ for TG; $\mathrm{p}=0.007, \mathrm{r}=-0.218$ for VLDL-C). Our analysis showed that white blood cell was positively correlated with leptin $(\beta=17.36, \mathrm{p}=0.048)$. Also, other $\mathrm{CBC}$ parameters had no significant correlations with BMI and leptin.

Conclusion: According to the findings of this study, BMI had a negative association with urea and HDL-C, while BMI had a positive association with insulin, hematocrit, FBS, uric acid, TG, VLDL-C, LDL-C, and ALT. Furthermore, leptin had a negative association with hematocrit, creatinine, and urea, TG, VLDL-C and a positive association with LDL-C and insulin among the participants of this study.

Keywords: Obesity, Overweight, Complete blood count, Leptinn

Conflicts of Interest: None declared

Funding: Iran University of Medical Sciences

\section{*This work has been published under CC BY-NC-SA 1.0 license.}

Copyright $\odot$ Iran University of Medical Sciences

Cite this article as: Zarrati M, Aboutaleb N, Cheshmazar E, Shokouhi Shoormasti R, Razmpoosh E, Nasirinezhad F. The association of obesity and serum leptin levels with complete blood count and some serum biochemical parameters in Iranian overweight and obese individuals. Med $J$ Islam Repub Iran. 2019 (22 Jul);33:72. https://doi.org/10.47176/mjiri.33.72

\section{Introduction}

Obesity is clearly a serious public health concern

\footnotetext{
1. Faculty of Nutrition, School of Public Health, Iran University of Medical Sciences, Tehran, Iran

2. Physiology Research Center, Iran University of Medical Sciences, Tehran, Iran

3. Immunology, Asthma and Allergy Research Institute, Tehran University of Medical Sciences, Tehran, Iran

4. Nutrition and Food Security Research Center, Shahid Sadoughi University of Medical Sciences, Yazd, Iran

5. Department of physiology, Basic Science Center, Iran University of Medical Sciences, Tehran, Iran
}

worldwide; and it has been estimated that the prevalence

$\uparrow$ What is "already known" in this topic:

The relationship between obesity and high concentrations of leptin has been confirmed.

\section{$\rightarrow$ What this article adds:}

High concentrations of leptin and BMI may be associated with abnormal changes in biochemical parameters levels. 
of overweight and obesity will increase to $25 \%$ and $32 \%$, respectively, in 2030 (1). Obesity is characterized by hypertrophy and hyperplasia of adipocytes, which are proinflammatory states related to metabolic and cardiovascular disorders, such as type 2 diabetes, hypertension, atherosclerosis, dyslipidemia, and acute and chronic inflammatory processes (1). Leptin, as a 16-KD protein, is a hormone produced by adipocytes, which are directly related to the amount and percentage of body fat; this protein circulates in the body and leads to reduced body weight through appetite, depression, and increased metabolic activity. On the other hand, the systemic effects of leptin is apart from those related to energy homeostasis, including immune function regulation of neuroendocrine, hematopoietic, and reproductive system $(2,3)$.

Current data have proved that the immune response may be influenced by leptin. Therefore, the express of leptin receptors is regulated in human peripheral blood mononuclear cells, intermediating the leptin outcome on proliferation and activation (2). Leptin has a significant direct proliferative effect on hematopoietic stem cells in the early stages of hematopoietic development and can stimulate the differentiation of cells of erythrocytes and myeloid lineage (4-6).

White blood cells (WBC) are immune defense system cells that play an important role in the inflammatory process (7); WBC count has a positive association with insulin resistance, hypertension, and cardiovascular disease, while it is unclear whether these alterations can fall out in healthy obese individuals $(8,9)$.

The bone marrow, which is located throughout the skeletal mass, is one of the largest and most active tissues in the body. Although complex differentiation pathways originate with hematopoietic stem cells, the bone marrow produces billions of new leukocytes and erythrocytes each day (10).

High red blood cells and hematocrit have been assumed to contribute to insulin resistance by rheological shifts and disturbed tissue blood flow $(11,12)$. Also, red blood cell count, hematocrit, and hemoglobin have been reported to be positively associated with insulin resistance $(13,14)$.

Among obese individuals, the levels of WBC, which include neutrophils, eosinophils, monocytes and lymphocytes, might be important in assessing the development of inflammation or diseases (15).

Considering that the elevated leptin levels with obesity is widely interpreted as the evidence of leptin resistance and also taking into account the role of CBC parameters (WBC and platelet) in inflammatory and thrombose in obesity, this study was conducted to assess these interactions.

This study was conducted to assess the relationship of clinical, biochemical, and $\mathrm{CBC}$ parameters with serum leptin levels and BMI in overweight and obese individuals.

\section{Methods \\ Participants}

This cross sectional prospective study was performed among Iranians recruited from the Clinical Nutrition De- partment at Iran University of Medical Sciences in Tehran, Iran. The main researcher described the study procedure and protocol, benefits, and risks to those willing to participate in the study; eligibility criteria were as follow: age 18- 60 years; voluntarily participation; signing an informed consent. Exclusion criteria were as follow: severe infectious or inflammatory diseases; cancers; secondary causes of obesity; pregnancy or lactation; evidence of severe hepatic or renal diseases; using medications or hormone therapy, including antihypertensive drugs, oral hypoglycemic and hypolipidemic agents; and using dietary supplements and insulin. The study group included 189 eligible Iranian males and females aged 18-60 years who were enrolled for the study. The participants were allocated into 3 groups based on their BMI $\left(\mathrm{kg} / \mathrm{m}^{2}\right)$ : normal group: $18.5<\mathrm{BMI}<24.9$; overweight: $25<\mathrm{BMI}<29.5$; and obese group: BMI $>30$. Dietary patterns of individuals were assessed using FFQ, 24-hour recall, and physical activity with PAQ questionnaires. Also, food intake and physical activity were assessed as confounding factors. Sample size was calculated using the below formula:

$$
\begin{gathered}
N=\left[\frac{Z \alpha+Z \beta}{C}\right]^{2}+3 \\
Z \alpha=1.960 \\
Z \beta=0.842 \\
C=0.5 * \ln [(1+r) /(1-r)]=0.203 \\
r \text { (correlation coefficient) }=0.2
\end{gathered}
$$

\section{Ethics statements}

This trial was performed according to the principles of the Declaration of Helsinki and the study protocol was approved by the Ethics Committee of Iran University of Medical Sciences (IUMS) (Ethic number 94-02-2726191). The study protocol was carefully explained to all participants before obtaining the informed consent. This study was registered on the Iranian website (www.irct.ir) for registration of clinical trials.

\section{Assessment of anthropometric measures}

Weight, height, hip, and waist circumferences were measured without heavy clothing and shoes; height and weight were measured to the nearest $0.1 \mathrm{~cm}$ and 0.1 $\mathrm{kg}$, respectively, using an automatic height-weight scale. Waist circumference measurement was taken midway between the lower rib margin and the superior iliac spine at the end of gentle expiration in a standing position, and hip circumference was measured at the widest part of the hip region; waist to hip ratio (WHR) was also calculated. BMI was computed as weight $(\mathrm{kg})$ divided by height in meters squared $\left(\mathrm{m}^{2}\right)$. Blood pressure (BP) was measured using a sphygmomanometer after participants had been in a relaxed state for at least 10 minutes.

\section{Biochemical measurements}

After obtaining consent from 184 individuals, fasting blood samples $(20 \mathrm{~mL})$ were obtained in vacutainer tubes with EDTA (Greiner VACUETTE EDTA) in the early morning after a 14-hour overnight fasting. Blood samples 
were centrifuged and stored at $-80^{\circ} \mathrm{C}$ before analysis at the IUMS reference laboratory.

The concentration of leptin was determined using a leptin ELISA Kit (e-bioscience, USA).

Serum triglyceride, high-density lipoprotein (HDL)cholesterol, low-density lipoprotein (LDL) cholesterol, and glucose levels were determined using an enzymaticcolorimetric test. The levels of uric acid, urea, creatinine, BUN, and plasma concentrations of SGOT, SGPT, and ALP were measured by biochemistry methods (autoanalyzer BT1500, Biotecnica Co, Italy). CBC were counted by a Coulter counter (Coulter International Corporation, Miami, FL, USA).

\section{Statistical analysis}

Statistical analysis was performed using SPSS software (Version 18.0; SPSS Inc. Chicago, IL, USA). To ensure the normal distribution of variables, the KolmogorovSmirnov test was used. Mean \pm SD and median $(Q 1, Q 3)$ were calculated for variables with normal and non-normal distribution, respectively. The association between 2 quantitative variables was measured using bivariate correlation (Pearson or Spearman). Logarithmic transformation was performed for some variables with non-normal distribution. Pearson correlations and multiple regression analysis were performed to assess the correlation between the variables. P-value $<0.05$ was considered significant. Simple and multiple regression analyses were performed to predict some variables.

\section{Results}

A total of 184 participants aged $18-60$ years [ 83 males (45.1\%) and 101 females (54.9\%)] participated in the study. Mean values of their age, weight, and BMI were $37.61 \pm 10.23$ years, $80.36 \pm 17.62(\mathrm{~kg})$, and $29.42 \pm 5.71$ $(\mathrm{kg} / \mathrm{m} 2)$, respectively. Baseline characteristics of participants are presented in Table 1.

Table 1. Baseline characteristics of the participants

\begin{tabular}{|c|c|c|c|c|}
\hline Variable & & Mean \pm SD & \multicolumn{2}{|c|}{$\operatorname{Median}\left(\mathrm{Q}_{1}, \mathrm{Q}_{3}\right)$} \\
\hline Weight $(\mathrm{kg})$ & & $80.36 \pm 17.62$ & \multirow{2}{*}{\multicolumn{2}{|c|}{$163(158,173.8)$}} \\
\hline Height $(\mathrm{cm})$ & & & & \\
\hline $\mathrm{BMI}\left(\mathrm{Kg} / \mathrm{m}^{2}\right)$ & & $29.42 \pm 5.71$ & \multirow{2}{*}{\multicolumn{2}{|c|}{$91(80.25,101.75)$}} \\
\hline Waist circumference $(\mathrm{cm})$ & & & & \\
\hline Wrist $(\mathrm{cm})$ & & & \multicolumn{2}{|c|}{$17(15.5,18)$} \\
\hline $\mathrm{SBP}(\mathrm{mmHg})$ & & & \multicolumn{2}{|c|}{$120(110,120)$} \\
\hline $\mathrm{DBP}(\mathrm{mmHg})$ & & & \multicolumn{2}{|c|}{$80(75,80)$} \\
\hline Hips $(\mathrm{cm})$ & & $108.64 \pm 11.62$ & \multirow{2}{*}{\multicolumn{2}{|c|}{$75(68,83)$}} \\
\hline FBS (mg/dl) & & & & \\
\hline Urea (mg/dl) & \multicolumn{2}{|r|}{$27.61 \pm 9.84$} & & \\
\hline Creatinine $(\mathrm{mg} / \mathrm{dl})$ & \multicolumn{2}{|r|}{$0.92 \pm 0.16$} & & \\
\hline Uric Acid (mg/dl) & \multicolumn{2}{|r|}{$5.06 \pm 1.37$} & & \\
\hline Leptin $(\mathrm{ng} / \mathrm{mL})$ & & & \multicolumn{2}{|c|}{$9.4(4,19.2)$} \\
\hline Cholesterol (mg/dl) & \multicolumn{2}{|r|}{$182.33 \pm 37.43$} & \\
\hline Triglyceride (mg/dl) & & & \multirow{2}{*}{\multicolumn{2}{|c|}{$135(100,195)$}} \\
\hline HDL-C (mg/dl) & \multicolumn{2}{|r|}{$47.16 \pm 13.52$} & & \\
\hline LDL-C (mg/dl) & \multicolumn{2}{|r|}{$103.97 \pm 32.80$} & \\
\hline VLDL-C (mg/dl) & & & \multicolumn{2}{|c|}{$27(19,39)$} \\
\hline LDL-C / HDL-C & \multicolumn{2}{|r|}{$2.36 \pm 0.94$} & \multirow{5}{*}{\multicolumn{2}{|c|}{$\begin{array}{c}23(20,28) \\
19(14,25.25) \\
186(156.5,221.5) \\
\end{array}$}} \\
\hline TC / HDL-C & \multicolumn{2}{|r|}{$4.14 \pm 1.30$} & & \\
\hline SGOT(AST) (U/L) & & & & \\
\hline SGPT(ALT) (U/L) & & & & \\
\hline Alkaline phosphatase (U/L) & & & & \\
\hline \multirow{2}{*}{\multicolumn{5}{|c|}{$\begin{array}{l}\text { Body Mass Index (BMI), Systolic Blood Pressure (SBP), Diastolic Blood Pressure (DBP), Waist Circumference (WC), High Density Lipoprotein } \\
\text { Density Lipoprotein (LDL), Very Low Density Lipoprotein (VLDL), Alanin Amino Transferas (ALT), Aspartat Amino Transferas (AST) } \\
\text { Table 2. Pearson correlation coefficients between complete blood count and some biochemical parameters with BMI and leptin }\end{array}$}} \\
\hline & & & & \\
\hline \multirow[t]{2}{*}{ Variables } & \multicolumn{2}{|c|}{ BMI } & & \\
\hline & $\mathrm{r}$ & $\mathrm{P}^{1}$ & $\mathrm{r}$ & $\mathrm{P}^{1}$ \\
\hline WBC $\left(\times 10^{9} / 1\right)$ & 0.129 & 0.081 & 0.160 & 0.055 \\
\hline $\mathrm{RBC}\left(\times 10^{12} / 1\right)$ & 0.109 & 0.144 & -0.156 & 0.059 \\
\hline Hemoglobin (g/dl) & -0.049 & 0.523 & -0.075 & 0.363 \\
\hline Hematocrit & 0.149 & 0.041 & -0.162 & 0.040 \\
\hline Platelet $\left(\times 10^{9} / 1\right)$ & -0.035 & 0.631 & 0.085 & 0.301 \\
\hline Insulin (mIU/l) & 0.520 & $\leq 0.001$ & 0.114 & 0.013 \\
\hline $\mathrm{FBS}(\mathrm{mg} / \mathrm{dL})$ & 0.363 & $\leq 0.001$ & -0.038 & 0.647 \\
\hline Urea (mg/dL) & -0.368 & $\leq 0.001$ & -0.305 & $\leq 0.001$ \\
\hline Creatinine (mg/dL) & -0.041 & 0.581 & -0.219 & 0.007 \\
\hline Uric Acid (mg/dL) & 0.309 & $\leq 0.001$ & -0.068 & 0.401 \\
\hline Triglyceride (mg/dL) & 0.189 & 0.015 & -0.188 & 0.025 \\
\hline HDL-C (mg/dL) & -0.297 & $\leq 0.001$ & 0.092 & 0.252 \\
\hline LDL-C (mg/dL) & 0.161 & 0.030 & 0.194 & 0.011 \\
\hline VLDL-C (mg/dL) & 0.181 & 0.019 & -0.218 & 0.007 \\
\hline Alkaline phosphatase (IU/L) & 0.052 & 0.492 & -0.088 & 0.289 \\
\hline SGOT(AST)(U/L) & 0.130 & 0.087 & -0.077 & 0.346 \\
\hline SGPT(ALT) (U/L) & 0.299 & $\leq 0.001$ & -0.043 & 0.599 \\
\hline
\end{tabular}

${ }^{1}$ Obtained from Pearson's correlation analysis. 
Table 3. Multiple regression analysis between complete blood count parameters with BMI and leptin

\begin{tabular}{|c|c|c|c|c|c|c|}
\hline & \multicolumn{3}{|c|}{ BMI } & \multicolumn{3}{|c|}{ Leptin } \\
\hline & $\beta$ & $95 \% \mathrm{CI}$ & $\mathrm{P}^{1}$ & $\beta$ & $95 \% \mathrm{CI}$ & $\mathrm{P}^{1}$ \\
\hline \multicolumn{7}{|l|}{ WBC $\left(\times 10^{9} / 1\right)$} \\
\hline Crude & 31.99 & $-4.65,68.63$ & 0.048 & 17.36 & $0.64,34.08$ & 0.042 \\
\hline Adjusted $^{2}$ & 28.33 & $-6.91,63.59$ & 0.032 & 17.02 & $0.90,33.14$ & 0.035 \\
\hline \multicolumn{7}{|l|}{$\operatorname{RBC}\left(\times 10^{12} / 1\right)$} \\
\hline Crude & 0.01 & $-0.004,0.205$ & 0.144 & -0.006 & $-0.013,0.00$ & 0.060 \\
\hline Adjusted & -0.001 & $-0.01,0.009$ & 0.892 & -0.003 & $-0.008,0.002$ & 0.222 \\
\hline \multicolumn{7}{|c|}{ Hemoglobin (g/dL) } \\
\hline Crude & -0.769 & $-3.12,1.58$ & 0.523 & -0.508 & $-1.73,0.71$ & 0.414 \\
\hline Adjusted & -0.58 & $-2.97,1.80$ & 0.635 & -0.386 & $-1.63,0.86$ & 0.542 \\
\hline \multicolumn{7}{|c|}{ Hematocrit (\%) } \\
\hline Crude & 0.093 & $0.001,0.186$ & 0.045 & -0.031 & $-0.075,0.012$ & 0.157 \\
\hline Adjusted & 0.039 & $-0.024,0.101$ & 0.221 & -0.004 & $-0.036,0.027$ & 0.786 \\
\hline \multicolumn{7}{|c|}{ Platelet $\left(\times 10^{9} / 1\right)$} \\
\hline Crude & -328.61 & $-1710,1052$ & 0.631 & 152.77 & $-526,832$ & 0.659 \\
\hline Adjusted & -404.1 & $-1715,907$ & 0.547 & -217.82 & $-872,436$ & 0.519 \\
\hline
\end{tabular}

RBC: Red Blood Cell, WBC: White Blood Cell

${ }^{1}$ Obtained from multiple regression analysis.

${ }^{2}$ After controlled mutual effect of other biochemical indicators as covariates.

This study indicated that hematocrit, insulin, FBS, uric acid, TG, LDL-C, VLDL-C, and ALT were positively correlated with BMI $(\mathrm{P}=0.041, \mathrm{r}=0.149$ for hematocrit; $\mathrm{p} \leq 0.001, \mathrm{r}=0.520$ for insulin; $\mathrm{p} \leq 0.001, \mathrm{r}=0.363$ for $\mathrm{FBS}$; $\mathrm{p} \leq 0.001, \mathrm{r}=0.309$ for uric acid; $\mathrm{p}=0.015, \mathrm{r}=0.189$ for $\mathrm{TG}$; $\mathrm{p}=0.030, \mathrm{r}=0.161$ for LDL-C; $\mathrm{p}=0.019, \mathrm{r}=0.181$ for VLDL-C; $\mathrm{p} \leq 0.001, \mathrm{r}=0.299$ for ALT), whereas urea and HDL-C were negatively associated with BMI $(p \leq 0.001$, $\mathrm{r}=-0.368$ for urea; $\mathrm{p} \leq 0.001, \mathrm{r}=-0.297$ for HDL-C). Moreover, LDL-C and insulin were positively correlated with leptin $(\mathrm{p}=0.011, \mathrm{r}=0.194$ for LDL-C; $\mathrm{p}=0.013, \mathrm{r}=0.114$ for insulin), and hematocrit, urea, creatinine, $\mathrm{TG}$, and VLDL-C were negatively correlated with leptin $(\mathrm{p}=0.040$, $\mathrm{r}=-0.162$ for hematocrit; $\mathrm{p} \leq 0.001, \mathrm{r}=-0.305$ for urea; $\mathrm{p}=0.007, \mathrm{r}=-0.219$ for creatinine; $\mathrm{p}=0.025, \mathrm{r}=-0.188$ for TG; $\mathrm{p}=0.007, \mathrm{r}=-0.218$ for VLDL-C) (Table 2).

Simple linear regression analysis showed that among the $\mathrm{CBC}$ parameters, only hematocrit was positively correlated with BMI $(\beta=0.093, p=0.045)$. However, this relationship did not remain significant after monitoring for other biochemical indicators $(\beta=0.039, p=0.221)$. Also, simple linear regression analysis showed that white blood cell was positively correlated with leptin $(\beta=17.36$, $\mathrm{p}=0.048)$. Similarly, this result was statistically significant for WBC $(\beta=17.02, p=0.032)$ after adjusting for other biomarkers (Table 3$)$.

Multiple regression analysis revealed that other $\mathrm{CBC}$ parameters had no significant correlations with BMI and leptin (Table 3).

Simple linear regression analysis revealed that among the biochemical measures in obese and overweight participants, serum urea and HDL-C were negatively correlated with BMI $(\beta=-0.636, p \leq 0.001$ for urea; $\beta=-0.707, p \leq 0.001$ for HDL-C) and serum insulin, FBS, uric acid, TG, ALT, LDL-C and VLDL-C levels were positively correlated with BMI $(\beta=0.782, p \leq 0.001$ for insulin; $\beta=0.966$, $\mathrm{p} \leq 0.001$ for FBS; $\beta=0.075, \mathrm{p} \leq 0.001$ for uric acid, $\beta=2.85$, $\mathrm{p}=0.014$ for $\mathrm{TG}, \beta=0.563, \mathrm{p} \leq 0.001$ for $\mathrm{ALT}, \beta=0.925$, $\mathrm{p}=0.034$ for LDL-C; $\beta=0.519, \mathrm{p} \leq 0.010$ for VLDL-C) $(\mathrm{Ta}-$ ble 4); these correlation continued to be significant even after controlling for other biochemical indicators ( $\beta=0.654, p \leq 0.001$ for insulin; $\beta=0.874, p=0.001$ for FBS; $\beta=-0.390, p=0.010$ for urea), while the association of uric acid, TG, LDL-C, HDL-C, ALT and VLDL-C disappeared (Table 4).

Moreover, simple linear regression analysis showed that

Table 4. Multiple regression analysis between some biochemical parameters with BMI and leptin

\begin{tabular}{|c|c|c|c|c|c|c|}
\hline & & $\mathrm{BMI}$ & & & Leptin & \\
\hline & $\beta$ & $95 \% \mathrm{CI}$ & $\mathrm{P}^{1}$ & $\beta$ & $95 \% \mathrm{CI}$ & $\mathrm{P}^{1}$ \\
\hline \multicolumn{7}{|c|}{ Insulin (mIU/l) } \\
\hline Crude & 0.782 & $0.615,0.949$ & $\leq 0.001$ & 0.114 & $0.024,0.204$ & 0.013 \\
\hline \multicolumn{7}{|l|}{ FBS (mg/dL) } \\
\hline Crude & 0.966 & $0.572,1.36$ & $\leq 0.001$ & -0.031 & $-0.217,0.155$ & 0.741 \\
\hline Adjusted & 0.874 & $0.355,1.39$ & 0.001 & -0.107 & $-0.308,0.093$ & 0.291 \\
\hline Crude & -0.636 & $-0.878,-0.395$ & $\leq 0.001$ & -0.219 & $-0.340,-0.098$ & $\leq 0.001$ \\
\hline Adjusted & -0.390 & $-0.685,-0.094$ & 0.010 & -0.119 & $-0.227,-0.011$ & 0.031 \\
\hline \multicolumn{7}{|c|}{ Creatinine (mg/dL) } \\
\hline Crude & -0.001 & $-0.005,0.003$ & 0.587 & -0.002 & $-0.004,0.00$ & 0.066 \\
\hline Adjusted & -0.001 & $-0.006,0.004$ & 0.693 & 0.00 & $-0.002,0.002$ & 0.811 \\
\hline \multicolumn{7}{|c|}{ Uric Acid (mg/dL) } \\
\hline Adjusted & -0.109 & $-0.324,0.542$ & 0.612 & 0.085 & $-0.070,0.24$ & 0.280 \\
\hline
\end{tabular}




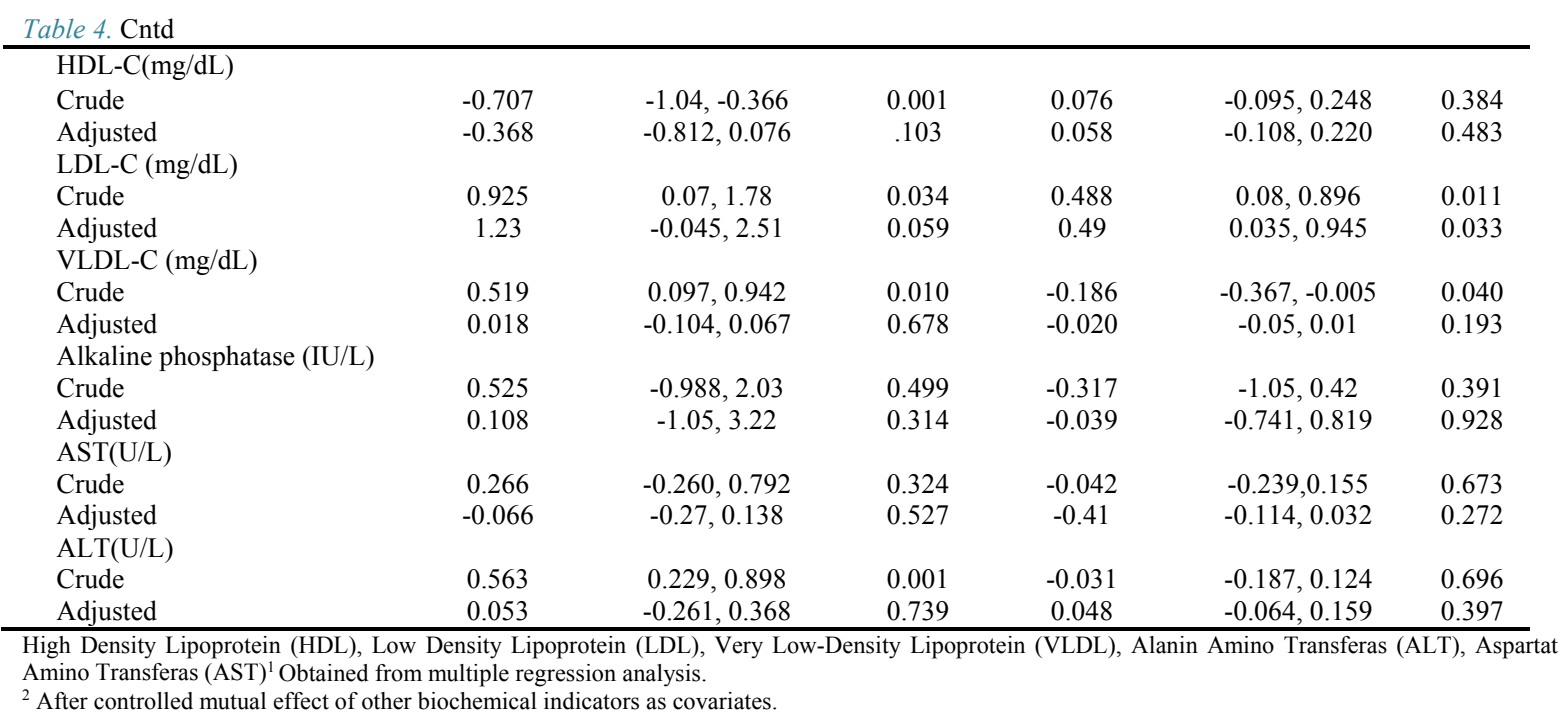

serum WBC, insulin, and LDL-C levels were positively correlated with leptin $(\beta=17.36, p=0.042$ for $\mathrm{WBC}$; $\beta=0.114, p=0.013$ for insulin; $\beta=0.488, p=0.011$ for LDLC) and serum urea, creatinine, TG, and VLDL-C were negatively correlated with leptin $(\beta=-0.219, p<0.001$ for urea; $\beta=-0.002, p=0.066$ for creatinine, $\beta=-0.876, p=0.060$ for TG; $\beta=-0.186, p=0.040$ for VLDL-C). These associations persisted to be significant even after controlling for other biochemical indicators $(\beta=17.02, p=0.035$ for $\mathrm{WBC}$; $\beta=0.093, p=0.046$ for insulin; $\beta=-0.119, p=0.031$ for urea; $\beta=0.498, p=0.033$ for LDL-C); however, the related significant results for VLDL-C and TG disappeared (Tables $3,4)$.

Multiple linear regression analysis demonstrated that BMI had no significant relationship with creatinine and alkaline phosphatase. In addition, non-significant differences were observed between serum leptin levels and either of HDL-C, alkaline phosphatase, uric acid, and FBS (Table 4).

\section{Discussion}

The aim of this study was to evaluate the relationship among clinical, biochemical, and CBC parameters with serum leptin levels and BMI in overweight and obese individuals.

This study indicated that BMI had a significant association with the levels of hematocrit, HDL-C, TG, and VLDL-C, insulin, ALT, LDL-C, FBS, uric acid, and urea.

In this study, no significant associations were found between WBC and BMI among participants. Obesity is a chronic disease with multifactorial etiologies that accompanies nutrients accumulation, which can lead to the aggregation of excess energy in the form of fat mass (16). Contrary to our results, several lines of evidence have supported a positive link between WBC count and BMI $(17,18)$

According to the results of this study, there was a poor positive correlation between BMI and hematocrit among participants, while no significant associations were observed between BMI and platelet counts. Farhangi et al (19) found that the levels of platelet counts were signifi- cantly higher among obese individuals compared to the non-obese; in fact, there is a current debate on whether obesity is accompanied with platelet activation (20). Higher concentrations of adipose tissue result in releasing inflammatory markers, which may contribute to atherogenesis and thrombosis through its effects on platelet activation (20).

The contradiction between the results of our study and those of previous ones might be due to the differences in BMI ranges and gender of participants. Differences in BMI may partly explain the differences of the observed associations between BMI and WBC. While the average BMI of obese participants in this study was $29.16 \mathrm{~kg} / \mathrm{m}^{2}$, the mean BMI of obese participants in the study of Neiman et al, who showed a positive correlation between WBC count and BMI, was $33.2 \mathrm{~kg} / \mathrm{m}^{2}$ (18).

On the other hand, this study revealed that leptin had no significant associations with hemoglobin, which do not support previous researches.

Tungtrongchitr and Toko $(21,22)$ reported a negative correlation between hemoglobin and serum leptin levels in overweight and obese males and females. Although bone marrow contains many adipocytes, their exact role is not clear (21). Considering the epidemiologic findings and related in vitro studies, leptin might play some roles in hematopoiesis in humans $(5,23)$.

Recent studies demonstrated that leptin might be able to accelerate arterial thrombosis, suggesting a mechanism for atherothrombotic disease in obesity $(24,25)$. Considering the existence of the long form of leptin receptor on the platelet membrane, it may be possible that leptin promotes the aggregation of human platelets through the activation of its receptor (26). Thus, the survey of leptin effects on platelet function may offer new insights into the mechanisms linking obesity and cardiovascular diseases.

In addition, a significant correlation was found between leptin and WBC in participants of this study; this result is in agreement with that of the previous studies $(27,28)$.

In obese individuals, the higher levels of WBC may be related to increased leptin concentration. Leptin may interfere in hematopoiesis, inflammation, or immunologic re- 
action in humans (27).

In this study, BMI showed a significant association with the levels of TG, HDL-C, LDL-C, and VLDL-C, suggesting that total cholesterol and TG levels were correlated with WHR measure, which is considered as an index for body fat distribution and visceral adiposity (29). Numerous reports have shown that higher levels of abdominal fat have been associated with elevated plasma TG concentration and lower HDL-C levels (30-32). These associations could also help explain the association between regional body fat distribution and cardiovascular diseases. Recent prospective studies have indicated that body fat distribution is significantly associated with cardiovascular diseases $(33,34)$.

It has been suggested that the significant positive association between the levels of VLDL-C and BMI, which is associated with the excess abdominal fat, may indirectly be due to an increased free fatty acid (FFA) flux from the omental adipocytes to the liver $(35,36)$. Elevated plasma VLDL levels, followed by increased free fatty acid, has also been associated with a reduced hepatic extraction of insulin (37).

The present data indicated that the levels of serum ALT, urea, and uric acid had a significant correlation with BMI in obese and overweight individuals; in accordance with our results, previous findings also demonstrated the same correlation (38-40). Obesity and central body fat distribution were associated with hyperuricemia $(41,42)$. Li-ying (43) reported that elevated waist circumference could result in higher risk of hyperuricemia.

Although the exact mechanisms of the elevated serum uric acid in obesity have not been fully clarified (41), several reasons have been suggested (41, 44-46). First, the rise of uric acid due to impairment of urinary urate excretion can be an important factor underlying hyperuricemia in obesity (47). Second, insulin resistance may be another cause of high serum uric acid level as the presence of hyperinsulinemia may decrease the urinary urate excretion $(45,48)$. Last of all, the aggregation of visceral fat is closely related to the incremented production of uric acid (UA), which may lead to hyperuricemia in obesity (41).

The mentioned association in this study was stronger in females than in males in both overweight and obese participants, which was inconsistent with published findings in different countries, such as Thailand (Bangkok) and China $(40,49,50)$.

Several researchers conducted studies to assess the relationship between leptin (gene production of obesity) and the cluster of hyperuricemia to elucidate the pathogenic mechanisms of the association of obesity with hyperuricemia. They found that serum uric acid concentration is independently related to serum leptin concentration (51, 52). However, they were unable to prove the mentioned association; it was specifically indicated that leptin could be a pathogenic factor responsible for hyperuricemia in obese patients $(51,52)$.

Furthermore, our findings are in line with previous studies which reported that ALT levels were more associated with BMI compared to AST levels (53-55). The most probable explanation for the relationship between serum
ALT levels and BMI could be related to visceral fat (56). Visceral fat accumulation is the strongest predictor of the elevated ALT concentrations among all the anthropometric variables, including BMI, while visceral adipose tissue, VAT, is the main predictor of the elevated ALT concentrations in the context of non-alcoholic fatty liver disease (57).

In the Western New York Health Study, ALT was reported to be more highly correlated with BMI than AST, particularly among men and postmenopausal women (55). Moreover, Burns et al (54), who performed 2 cross sectional analyses among men and women, also found a greater effect of BMI on the levels of ALT compared with AST.

In this study, it was demonstrated that serum insulin levels in obese and overweight people were positively correlated with leptin. The findings of this study on the relationship between insulin and leptin was inconsistent with a previous study, which reported that leptin might play a role in modulating serum insulin levels and insulin resistance (58). In addition, Karen et al (59) demonstrated that insulin resistance is linked with augmented plasma leptin concentrations. Although Kraen et al reported that insulin did not markedly regulate leptin production, the chronically elevated plasma insulin concentrations may stimulate the obese gene (ob gene) expression and increase the leptin concentration as its protein product (59).

According to the results of this study, there was a positive correlation between the levels of leptin and LDL-C, while no related correlations were found in a study by Ahmadi et al (60). The main reason explaining these differences are various characteristics of target populations, including obese and non-obese participants, type of patients, and different age groups.

On the other hand, we found that the levels of TG and VLDL-C were negatively correlated with leptin, while some human published studies (61-63) reported that leptin levels were directly associated with TG. Furthermore, in the study by Murtadha and Sarha (64), leptin was reported to be positively correlated with TG and VLDL-C levels (65).

Many existing criteria, including genetic factors, such as pleiotropy (ie, shared genes) and nongenetic factors (ie, shared environment) $(61,66)$, clinical differences of patients (65), sex (64), and age (61) could be accountable for the correlated relationship between leptin and lipid levels.

Based on the results of this study, urea and creatinine had negative correlations with leptin in obese and overweight people, while a related positive correlation was found in the study by Ahmadi et al (60).

Johansen et al did not report any correlations between leptin levels and urea or creatinine among hemodialysis male patients (67). Differences in health and disease status of the population, methods, and the kits used to measure leptin and other biochemical parameters, various methods for measuring serum or plasma leptin levels, and measuring free serum leptin or leptin, which is bounded to receptors, may be responsible for different results.

The potential strength of this study was that all the participants were obese and overweight. This study had sev- 
eral limitations. Firstly, because of the cross sectional nature of the study, there was no information about the causal relationship between variables, which needs to be elucidated in future prospective studies. Secondly, the final analysis was performed only among overweight and obese adults, indicating that these results cannot be extended to healthy-weight adults. Another limitation of this study was lack of a control group and only a descriptive study was conducted. Moreover, the blinding method was not used; thus, further controlled and blind studies with randomized design are required; cell line studies are also needed to confirm these correlations.

With regards to the increasing prevalence of obesity in the world and leptin resistance in obesity, more studies are urgently needed to clarify whether leptin has positive effects on the concentrations of CBC parameters and inflammation.

\section{Conclusion}

Despite some limitations in this study, the correlations of $\mathrm{CBC}$, lipid profiles, liver, and kidney parameters with the measurements of BMI and leptin were shown.

Moreover, there were significant differences in the levels of hematocrit, insulin, TG, HDL-C, VLDL-C, LDL-C, FBS, ALT, urea, and uric acid. Leptin levels were significantly correlated with insulin, WBC, urea and creatinine, TG, VLDL-C, and LDL-C. Leptin serum levels could play an important role in the etiopathogenesis of comorbidities, which are associated with the incidence of obesity.

Consequently, as the rate of obesity and its comorbidities are increasing, focusing on such strategies may lead to promises for reducing the non-communicable diseases via improving the life style, which prevents the incidence of obesity. Yet, further studies are required to confirm our findings and determine possible underlying mechanisms.

\section{Funding}

This study was funded by Iran University of Medical Sciences [Grant no. 94022726191].

\section{Ethical approval}

All procedures performed in studies involving human participants were in accordance with the ethical standards of the institutional and/or national research committee and with the 1964 Helsinki declaration and its later amendments or comparable ethical standards.

\section{Informed consent}

Informed consent was obtained from all individual participants included in the study.

\section{Conflict of interest}

The authors declare that they have no conflict of interest.

\section{References}

1. Oliveira TMS, Faria FRd, Faria ERd, Pereira PF, Franceschini SC, Priore SE. Nutritional status, metabolic changes and white blood cells in adolescents. Rev Paul Pediatr. 2014;32(4):351-9.
2. Sanchez-Margalet V, Martin-Romero C, Santos-Alvarez J, Goberna R, Najib S, Gonzalez-Yanes C. Role of leptin as an immunomodulator of blood mononuclear cells: mechanisms of action. Clin Exp Immunol. 2003;133(1):11-9.

3. Ahima RS, Flier JS. Leptin. Ann Rev Physiol. 2000;62(1):413-37.

4. Kinik ST, Özbek N, Yücel M, Haberal A, Çetintas S. Correlations among serum leptin levels, complete blood count parameters and peripheral CD34 $(+)$ cell count in prepubertal obese children. Ann Hematol. 2005;84(9):605-8.

5. Mikhail AA, Beck EX, Shafer A, Barut B, Gbur JS, Zupancic TJ, et al. Leptin stimulates fetal and adult erythroid and myeloid development. Blood. 1997;89(5):1507-12.

6. Konopleva M, Mikhail A, Estrov Z, Zhao S, Harris D, SanchezWilliams G, et al. Expression and function of leptin receptor isoforms in myeloid leukemia and myelodysplastic syndromes: proliferative and anti-apoptotic activities. Blood. 1999;93(5):1668-76.

7. Farhangi MA, Keshavarz SA, Eshraghian M, Ostadrahimi A, SaboorYaraghi AA. White blood cell count in women: relation to inflammatory biomarkers, haematological profiles, visceral adiposity, and other cardiovascular risk factors. J Health Popul Nutr. 2013;31(1):58.

8. Karthikeyan V, Lip G. White blood cell count and hypertension. J Hum Hypertens. 2006;20(5):310-2.

9. Sabatine MS, Morrow DA, Cannon CP, Murphy SA, Demopoulos LA, DiBattiste PM, et al. Relationship between baseline white blood cell count and degree of coronary artery disease and mortality in patients with acute coronary syndromes: A TACTICS-TIMI 18 substudy. JACC Clin Electrophysiol. 2002;40(10):1761-8.

10. Lodish H, Flygare J, Chou S. From stem cell to erythroblast: regulation of red cell production at multiple levels by multiple hormones. IUBMB Life. 2010;62(7):492-6.

11. Baron AD, Steinberg H, Brechtel G, Johnson A. Skeletal muscle blood flow independently modulates insulin-mediated glucose uptake. Am J Physiol Endocrinol Metab. 1994;266(2):E248-E53.

12. Gori T. Viscosity, platelet activation, and hematocrit: progress in understanding their relationship with clinical and subclinical vascular disease. Clin Hemorheol Microcirc..2011;49(1-4):37-42.

13. Barbieri M, Ragno E, Benvenuti E, Zito G, Corsi A, Ferrucci L, et al. New aspects of the insulin resistance syndrome: impact on haematological parameters. Diabetologia. 2001;44(10):1232-7.

14. Tamariz LJ, Young JH, Pankow JS, Yeh HC, Schmidt MI, Astor B, et al. Blood viscosity and hematocrit as risk factors for type 2 diabetes mellitus the Atherosclerosis Risk in Communities (ARIC) study. Am J Epidemiol. 2008;168(10):1153-60.

15. Zaldivar F, McMurray R, Nemet D, Galassetti P, Mills P, Cooper D. Body fat and circulating leukocytes in children. Int $\mathrm{J}$ Obes. 2006;30(6):906-11

16. Salehpour A, Hosseinpanah F, Shidfar F, Vafa M, Razaghi M, Dehghani S, et al. A 12-week double-blind randomized clinical trial of vitamin D 3 supplementation on body fat mass in healthy overweight and obese women. Nutr J. 2012;11(1):1.

17. Han SN, Jeon KJ, Kim MS, Kim HK, Lee AJ. Obesity with a body mass index under 30 does not significantly impair the immune response in young adults. Nutr Res. 2011;31(5):362-9.

18. Nieman DC, Henson DA, Nehlsen-Cannarella SL, Ekkens M, Utter $\mathrm{AC}$, Butterworth DE, et al. Influence of obesity on immune function. J Am Diet Assoc. 1999;99(3):294-9.

19. Farhangi MA, Keshavarz SA, Eshraghian M, Ostadrahimi A, Saboor-Yaraghi AA. White blood cell count in women: relation to inflammatory biomarkers, haematological profiles, visceral adiposity, and other cardiovascular risk factors. J Health Popul Nutr. 2013;31(1):58-64.

20. Samocha-Bonet D, Justo D, Rogowski O, Saar N, Abu-Abeid S, Shenkerman G, et al. Platelet counts and platelet activation markers in obese subjects. Mediators Inflamm. 2008;2008.

21. Togo M, Tsukamoto K, Satoh H, Hara M, Futamura A, Nakarai H, et al. Relationship between levels of leptin and hemoglobin in Japanese men. Blood. 1999;93(12):4444-5.

22. Tungtrongchitr R, Pongpaew P, Phonrat B, Tribunyatkul S, Viroonudomphol D, Supawan V, et al. Leptin concentration in relation to body mass index (BMI) and hematological measurements in Thai obese and overweight subjects. Southeast Asian J Trop Med Public Health. 2000 Dec;31(4):787-94. 
23. Bennett BD, Solar GP, Yuan JQ, Mathias J, Thomas GR, Matthews W. A role for leptin and its cognate receptor in hematopoiesis. Curr. Biol. 1996;6(9):1170-80.

24. Konstantinides S, Schäfer K, Koschnick S, Loskutoff DJ. Leptindependent platelet aggregation and arterial thrombosis suggests a mechanism for atherothrombotic disease in obesity. J Clin Invest. 2001;108(10):1533-40.

25. Bodary PF, Westrick RJ, Wickenheiser KJ, Shen Y, Eitzman DT. Effect of leptin on arterial thrombosis following vascular injury in mice. Jama. 2002;287(13):1706-9.

26. Nakata M, Yada T, Siejima N, Maruyama I. Leptin promotes aggregation of human platelets via the long form of its receptor. Diabetes. 1999;48(2):426.

27. Mabuchi T, Yatsuya H, Tamakoshi K, Otsuka R, Nagasawa N, Zhang $\mathrm{H}$, et al. Association between serum leptin concentration and white blood cell count in middle-aged Japanese men and women. Diabetes-Metab Res. 2005;21(5):441-7.

28. Perfetto F, Mancuso F, Tarquini R. Leukocytosis and hyperleptinemia in obesity: is there a link. Haematologica. 2002;87(5):ELT25-ELT.

29. Bertoli A, Di Daniele N, Ceccobelli M, Ficara A, Girasoli C, De Lorenzo A. Lipid profile, BMI, body fat distribution, and aerobic fitness in men with metabolic syndrome. Acta Diabetol. 2003;40(1):s130-s3

30. Anderson AJ, Sobocinski KA, Freedman DS, Barboriak JJ, Rimm AA, Gruchow HW. Body fat distribution, plasma lipids, and lipoproteins. Arterioscler Thromb Vasc Biol . 1988;8(1):88-94.

31. Despres J, Tremblay A, Perusse L, Leblanc C, Bouchard C. Abdominal adipose tissue and serum HDL-cholesterol: association independent from obesity and serum triglyceride concentration. Int $\mathrm{J}$ Obes. 1987;12(1):1-13

32. Després JP, Allard C, Tremblay A, Talbot J, Bouchard C. Evidence for a regional component of body fatness in the association with serum lipids in men and women. Metabolism. 1985;34(10):967-73.

33. Donahue R, Bloom E, Abbott R, Reed D, Yano K. Central obesity and coronary heart disease in men. Lancet. 1987;329(8537):821-4.

34. Ducimetiere P, Richard J, Cambien F. The pattern of subcutaneous fat distribution in middle-aged men and the risk of coronary heart disease: the Paris Prospective Study. Int J Obes.1985;10(3):229-40.

35. Despres JP, Moorjani S, Ferland M, Tremblay A, Lupien PJ, Nadeau A, et al. Adipose tissue distribution and plasma lipoprotein levels in obese women. Importance of intra-abdominal fat. Arterioscler Thromb Vasc Biol. 1989;9(2):203-10.

36. Kissebah AH, Evans DJ, Peiris A, Wilson CR. Endocrine characteristics in regional obesities: role of sex steroids. Metabol Complicat Hum Obes. 1985:115-30

37. Peiris AN, Mueller RA, Smith GA, Struve MF, Kissebah A Splanchnic insulin metabolism in obesity. Influence of body fat distribution. J Clin Investig. 1986;78(6):1648.

38. Abdul-Majeed A. Relationship Between Uric Acid and Obesity. Iraq Acad Sci J. 2009;7(1):1

39. Duan Y, Liang $W$, Zhu L, Zhang T, Wang L, Nie Z, et al. Association between serum uric acid levels and obesity among university students (China). Nutr Hosp. Organo oficial de la Sociedad española de nutrición parenteral y enteral. 2015;31(6):2407-11.

40. Dai X, Yuan J, Yao P, Yang B, Gui L, Zhang X, et al. Association between serum uric acid and the metabolic syndrome among a middleand old-age Chinese population. Eur J Epidemiol. 2013;28(8):669-76.

41. Matsuura F, Yamashita S, Nakamura T, Nishida M, Nozaki S, Funahashi $\mathrm{T}$, et al. Effect of visceral fat accumulation on uric acid metabolism in male obese subjects: visceral fat obesity is linked more closely to overproduction of uric acid than subcutaneous fat obesity. Metabolism. 1998;47(8):929-33.

42. Bonora E, Targher G, Zenere M, Saggiani F, Cacciatori V, Tosi F, et al. Relationship of uric acid concentration to cardiovascular risk factors in young men. Role of obesity and central fat distribution. The Verona Young Men Atherosclerosis Risk Factors Study. Int J Obes. Relat Metab Disord. journal of the International Association for the Study of Obesity. 1996;20(11):975-80.

43. Chen LY, Zhu WH, Chen ZW, Dai HL, Ren JJ, Chen JH, et al. Relationship between hyperuricemia and metabolic syndrome. J Zhejiang Uni Sci B. 2007;8(8):593-8.

44. Facchini F, Chen YDI, Hollenbeck CB, Reaven GM. Relationship between resistance to insulin-mediated glucose uptake, urinary uric acid clearance, and plasma uric acid concentration. Jama. 1991;266(21):3008-11

45. Vuorinen-Markkola H, Yki-Järvinen H. Hyperuricemia and insulin resistance. J Clin Endocrinol Metab.1994;78(1):25-9.

46. Galvan AQ, Natali A, Baldi S, Frascerra S, Sanna G, Ciociaro D, et al. Effect of insulin on uric acid excretion in humans. Am J Physiol Endocrinol Metab. 1995;268(1):E1-E5.

47. Yamashita S, Matsuzawa Y, Tokunaga K, Fujioka S, Tarui S Studies on the impaired metabolism of uric acid in obese subjects: marked reduction of renal urate excretion and its improvement by a low-calorie diet. Int J Obes. 1985;10(4):255-64.

48. Modan M, Halkin H, Karasik A, Lusky A. Elevated serum uric acid - a facet of hyperinsulinaemia. Diabetologia. 1987;30(9):713-8.

49. Yin X, Zhou J, Yu D, Pan Q, Dong X, Zheng F, et al. [The correlation between serum uric acid level and abdominal obesity or metabolic syndrome]. Zhonghua Nei Ke Za Zhi. 2014;53(1):13-8.

50. Jaipakdee J, Jiamjarasrangsri W, Lohsoonthorn V, Lertmaharit S. Prevalence of metabolic syndrome and its association with serum uric acid levels in Bangkok Thailand. Southeast Asian J Trop Med Public Health. 2013;44(3):512-22.

51. Bedir A, Topbas M, Tanyeri F, Alvur M, Arik, Nurol. Leptin might be a regulator of serum uric acid concentrations in humans. Jpn Heart J. 2003;44(4):527-36.

52. Fruehwald-Schultes B, Peters A, Kern W, Beyer J, Pfützner A. Serum leptin is associated with serum uric acid concentrations in humans. Metabolism. 1999;48(6):677-80.

53. Lee DH, Ha MH, Christiani DC. Body weight, alcohol consumption and liver enzyme activity - a 4-year follow-up study. Int J Epidemiol. 2001;30(4):766-70

54. Burns CJ, Boswell JM, Olsen GW. Liver enzyme activity and body mass index. Int J Occup Environ Med. 1996;38(12):1248-52.

55. Stranges S, Dorn JM, Muti P, Freudenheim JL, Farinaro E, Russell $\mathrm{M}$, et al. Body fat distribution, relative weight, and liver enzyme levels: A population-based study. Hepatology. 2004;39(3):754-63.

56. Kim J, Jo I. Relationship between body mass index and alanine aminotransferase concentration in non-diabetic Korean adults. Eur J Clin Nutr. 2010;64(2):169-75.

57. Song HR, Yun KE, Park HS. Relation between alanine aminotransferase concentrations and visceral fat accumulation among nondiabetic overweight Korean women. Am J Clin Nutr. 2008;88(1):16-21.

58. Wang TN, Chang WT, Chiu YW, Lee CY, Lin KD, Cheng YY, et al. Relationships between changes in leptin and insulin resistance levels in obese individuals following weight loss. Kaohsiung $\mathrm{J}$ Med Sci. 2013;29(8):436-43.

59. Segal KR, Landt M, Klein S. Relationship between insulin sensitivity and plasma leptin concentration in lean and obese men. Diabetes. 1996;45(7):988-91.

60. Ahamadi F, Bosorgmehr R, Razeghi E. Relationship between serum leptin level and laboratory and anthropometric indices of malnutrition in patients on hemodialysis. Indian J Nephrol. 2008;18(3):105.

61. Wu DM, Shen MH, Chu NF. Relationship between plasma leptin levels and lipid profiles among school children in Taiwan-the Taipei Children Heart Study. Eur J Epidemiol. 2001;17(10):911-6.

62. Liuzzi A, Savia G, Tagliaferri M, Lucantoni R, Berselli M, Petroni $\mathrm{M}$, et al. Serum leptin concentration in moderate and severe obesity: relationship with clinical, anthropometric and metabolic factors. Int $\mathbf{J}$ Obes. 1999;23(10):1066-73.

63. Leyva F, Godsland IF, Ghatei M, Proudler AJ, Aldis S, Walton C, et al. Hyperleptinemia as a component of a metabolic syndrome of cardiovascular risk. Arterioscler Thromb Vasc Biol. 1998;18(6):92833.

64. Murtadha NA, Sarhat ER. Relationship between Leptin and Lipid Profile in Obese Females in Tikrit Province. Int J Curr Microbiol App Sci. 2016;5(5):493-501.

65. Dubey A, Kant S, Agarwal S, Mahdi AA, Tiwari S. Relationship Between Serum Leptin Level and Serum Lipid Profile in Male Obstructive Sleep Apnea Syndrome Patients. Indian J Clin Biochem. 2015;30(4):440-4.

66. Rainwater DL, Comuzzie AG, VandeBerg JL, Mahaney MC, Blangero J. Serum leptin levels are independently correlated with two measures of HDL. Atherosclerosis. 1997;132(2):237-43

67. Johansen KL, Mulligan K, Tai V, Schambelan M. Leptin, body composition, and indices of malnutrition in patients on dialysis. J Am Soc Nephrol. 1998;9(6):1080-4. 